\title{
IDENTIFIKASI KOMPONEN GUI PADA PROTOTIPE APLIKASI MOBILE
}

\author{
Mungki Astiningrum¹, Arie Rachmad Syulistyo², Aura Kanza Caesaria ${ }^{3}$ \\ 1,2,3 Program Studi Teknik Informatika, Jurusan Teknologi Informasi, Politeknik Negeri Malang \\ ${ }^{1}$ mungki.astiningrum@polinema.ac.id, ${ }^{2}$ arie.rachmad.s@polinema.ac.id, ${ }^{3}$ aurakanzaaa@gmail.com
}

\begin{abstract}
Abstrak
OS Android merupakan OS Mobile terpopuler sejumlah 71,6\% disusul IOS, dll. Hal ini menjadi peluang besar untuk menjadi android developer. Langkah awal yang harus dipersiapkan adalah memiliki pengetahuan dasar Java dan XML. Proses yang harus disiapkan pertama kali adalah pembuatan User Interface aplikasi. Namun, sebagai pemula sering kali kebingungan dalam menentukan komponen yang harus digunakan dalam pembuatan interface. Oleh karena itu diperlukan sebuah sistem yang dapat mengenali komponen yang akan digunakan.

Perkembangan ilmu pengetahuan dan teknologi pengolahan citra digital memungkinkan untuk mengklasifikasi komponen GUI secara otomatis dengan bantuan aplikasi pengolahan citra. Dalam pengenalan komponen ini digunakan metode Convolutional Neural Network (CNN). Metode ini dapat mengenali komponen pada sebuah image. Dengan adanya aplikasi ini dapat membantu pengguna dalam menentukan komponen yang akan digunakanan untuk membuat tampilan suatu aplikasi. Tingkat keberhasilan klasifikasi komponen GUI yang didapatkan menggunakan metode Convolutional Neural Network adalah 85.32\%. Sehingga dapat disimpulkan bahwa identifikasi komponen GUI pada prototipe aplikasi mobile sudah sesuai.
\end{abstract}

Kata kunci : Image Classification, Convolutional Neural Network, GUI

\section{Pendahuluan}

Perkembangan smartphone saat ini tumbuh sangat pesat, dengan munculnya berbagai inovasi teknologi dan berbagai macam produsen serta didukung oleh para pengembang aplikasi yang dapat meningkatkan kualitas serta kuantitas smartphone [1]. Ada berbagai macam sistem operasi yang tercipta hingga saat ini sistem operasi yang dikenal saat ini adalah Android dan IOS. Berdasarkan wearesocial.com saat ini OS Android merupakan $O S$ Mobile terpopuler di dunia dengan jumlah $71,6 \%$ disusul IOS dan OS mobile lainnya pada tahun 2017. Di Indonesia sendiri pada tahun 2017 pengguna Smartphone Android jumlahnya hampir $80 \%$. Tingginya pengguna Smartphone Android tentu saja software atau aplikasi sangat berperan dalam kegunaan smartphone.

Hal ini menjadi sebuah peluang besar untuk menjadi Android Developer. Agar dapat membuat sebuah aplikasi Android haruslah kita memiliki pengetahuan dasar Java dan XML. Pengetahuan ini sangat penting karena Bahasa Java dianggap sebagai Bahasa pemrograman dasar untuk pengembangan android. Sedangkan XML adalah Bahasa markup yang banyak digunakan dalam membuat tampilan suatu aplikasi. Dengan mempelajari sintak dasar XML akan membantu dan mempermudah dalam pengembangan aplikasi android seperti merancang layout tata letak antarmuka pengguna (UI) dan parsing data dari internet. Untuk membuat tampilan kita harus memahami aturan dasar dan bagaimana cara menulis XML dan cara membacanya.

Sebagai pemula seringkali kebingungan menentukan langkah awal yang harus dilakukan untuk membuat sebuah tampilan dan bagaimana cara membuatnya. Ingin membuat tampilan sederhana namun tidak tahu komponen yang harus digunakan didalamnya. Oleh karena itu diperlukan sebuah sistem yang dapat membantu proses pembelajaran dalam menentukan komponen yang akan digunakan dengan menggunakan pengolahan citra digital. Sistem dapat mengenali komponen yang terdapat dalam screenshot halaman aplikasi. Penulis mencoba mengangkat suatu ide dimana diperlukan metode untuk menganalisa objek dari inputan berupa potongan screenshot aplikasi untuk mengenali komponen apa saja yang terdapat didalamnya dan memberikan informasi pembuatan komponen berupa kode program. Untuk mengenali komponen dalam screenshot aplikasi, penulis mencoba menggunakan metode Convolutional Neural Network (CNN). Metode ini dapat mendeteksi dan mengenali objek pada sebuah image lebih baik karena dapat menciptakan suatu pola atau kemampuan belajar (self organizing). Dengan melakukan identifikasi komponen GUI menggunakan CNN diharapkan dapat membantu pengguna dalam menentukan 
komponen yang akan digunakan untuk membuat tampilan suatu aplikasi.

\section{Tinjauan Pustaka}

\subsection{Pengolahan Citra Digital (Image Processing)}

Sebuah gambar disebut dengan citra digital apabila gambar yang dihasilkan dari proses sebuah komputer, kamera, scanner atau perangkat elektronik lainnya. Pengolahan citra digital diproses oleh komputer dengan menggunakan algoritma. Citra digital direpresentasikan dengan matriks, sehingga pengolahan pada citra digital pada dasarnya memanipulasi elemen-elemen matriks. Operasi yang dapat dilakukan pada sebuah citra ada berbagai macam, diantaranya operasi titik, operasi global, operasi berbasis bingkai, operasi geometri dan operasi bertetangga [2]

\subsection{Prototipe}

Prototipe dapat di klik dan ketika anda mengklik, anda mendapat respon. Prototipe yang dapat di klik mensimulasikan bagaimana pengguna berinteraksi dengan antarmuka UI dengan cara yang nyata, meningkatkan efektivitas komunikasi anda. Ini memungkinkan desainer untuk menguji alur dan menemukan masalah terhadap interaksi pada tahap awal [3]

\subsection{Convolutional Neural Network

Convolutional Neural

Network

(CNN/ConvNet) adalah salah satu algoritma dari deep learning yang merupakan pengembangan dari Multilayer Percepton (MLP) yang dirancang untuk mengolah data dalam bentuk dua dimensi, misalnya gambar atau suara [4]

\section{- Convolution Layer}

Convolutional Layer terdiri dari neuron yang tersusun sedemikian rupa sehingga membentuk sebuah filter dengan panjang dan tinggi (pixels). Sebagai contoh layer pertama pada feature extraction layer biasanya adalah conv. Layers dengan ukuran $5 \times 5 \times 3$. Panjang 5 pixels, Tinggi 5 pixels dan tebal 3 buah sesuai dengan channel dari image tersebut. Untuk menghitung banyaknya neuron aktivasi dalam sekali output adalah sebagai berikut :

$$
\text { output }=\frac{W-N+2 P}{S}+1
$$

Keterangan :

$$
\begin{aligned}
& \mathrm{W}=\text { Panjang/ Tinggi Input } \\
& \mathrm{N}=\text { Panjang/ Tinggi Filter } \\
& \mathrm{P}=\text { zero } \text { padding } \\
& \mathrm{S}=\text { stride }
\end{aligned}
$$

\section{- $\quad$ Stride}

Stride adalah jumlah piksel yang bergeser di atas matriks input. Ketika stride 1 maka filter akan bergeser sejumlah 1 piksel. Ketika stride 2 maka piksel akan bergeser 2 piksel setelah matriks input seara vertical dan horizontal [5]. Dapat dilihat pada Gambar 1 yang merupakan ilustrasi pergeseran stride:

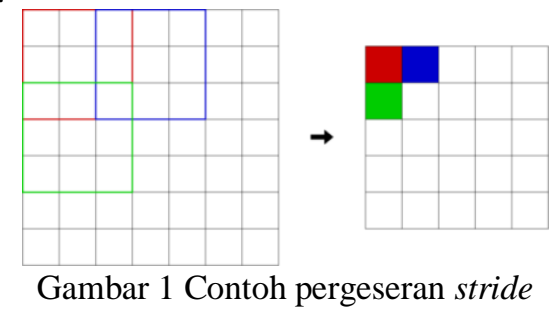

\section{- $\quad$ Padding}

Padding mengacu pada proses menambahkan angka nol secara simetris ke matriks input. Cara ini merupakan cara umum yang digunakan untuk mempertahankan ukuran spasial dari volume input sehingga input dan output ukurannya sama. Gambar 2 ini adalah contoh penambahan padding 2 :

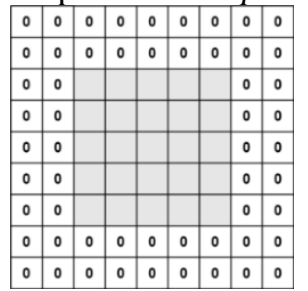

Gambar 2 zero-pading 5x5 menjadi 9x9

\section{- $\quad$ ReLU (Rectified Linear Units)}

Rectified Linear Unit adalah fungsi aktivasi yang paling umum digunakan dalam deep learning. Fungsinya mengembalikan nilai 0 jika menerima input negative, tetapi setiap nilai positif nilai $\mathrm{x}$ akan dikembalikan ke nilai aktivasi itu sendiri [6]. Jadi dapat ditulis dengan rumus berikut:

$$
f(x)=\max (0, x)
$$

\section{- Pooling Layer}

Pooling layer biasanya berada setelah conv layer. Pada prinsipnya pooling layer terdiri dari sebuah filter dengan ukuran dan stride tertentu yang akan bergeser pada seluruh area feature map. Pooling yang biasa digunakan adalah Max Pooling dan Average Pooling. Sebagai contoh jika kita menggunakan Max Pooling 2x2 dengan stride 2, maka pada setiap pergeseran filter, nilai maximum pada area $2 \times 2$ pixel tersebut yang akan dipilih, sedangkan Average Pooling akan memilih nilai rataratanya. Gambar 3 merupakan contoh gambar operasi max dan average pooling:

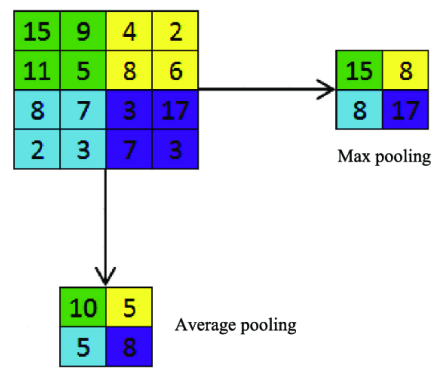

Gambar 3 Pooling Layer 
- $\quad$ Fully Connected Layer

Lapisan fully connected adalah lapisan di mana semua neuron aktivasi dari lapisan sebelumnya terhubung semua dengan neuron di lapisan selanjutnya seperti halnya jaringan saraf tiruan biasa. Setiap aktivasi dari lapisan sebelumnya perlu diubah menjadi data satu dimensi sebelum dapat dihubungkan ke semua neuron di lapisan. Dapat dilihat Gambar 4 merupakan proses dari Fully Connected Layer.

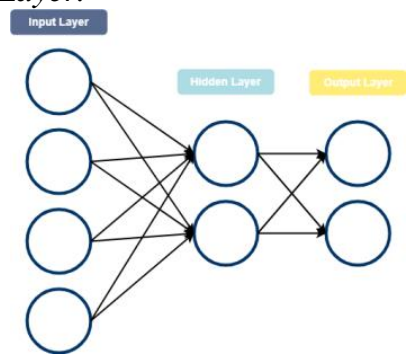

Gambar 4 Proses dari Fully Connected Layer

- Fungsi Aktivasi Softmax

Fungsi aktivasi softmax digunakan untuk mendapatkan hasil klasifikasi. Fungsi aktivasi menghasilkan nilai yang diinterpretasi sebagai probabilitas yang belum dinormalisasi untuk tiap kelas. Nilai kelas dihitung dengan menggunakan fungsi softmax [7]

\section{- Forward Propagation}

Proses forward propagation pada jaringan $\mathrm{CNN}$ dilakukan untuk meneruskan nilai pada lapisan masukan hingga pada lapisan keluaran. Nilai ini diteruskan melalui lapisan konvolusi, subsampling dan lapisan fully connected sesuai dengan urutan lapisan tersebut ditempatkan pada jaringan yang digunakan.

\section{- Backward Propagation}

Proses untuk memperbaharui nilai filter dan bobot pada jaringan adalah proes propagasi balik. Perhitungan perubahan nilai bobot dihitung dimulai dari lapisan fully connected. Pada lapisan ini perubahan bobot dicari dengan mencari derivatif loss function terhadap bobot [8].

- Confusion Matriks

Confusion matrix merupakan salah satu metode yang dapat digunakan untuk mengukur kinerja suatu metode klasifikasi. Pada dasarnya confusion matriks mengandung informasi yang membandingkan hasil klasifikasi yang dilakukan oleh sistem dengan hasil klasifikasi yang seharusnya [9].

\begin{tabular}{c|l||l|l|l}
\multicolumn{4}{c}{} & \multicolumn{3}{c}{ Predicted class } \\
\cline { 2 - 4 } Actual class & & $y e s$ & $n o$ & \multirow{2}{*}{ Total } \\
\cline { 2 - 4 } & $y e s$ & $T P$ & $F N$ & $P$ \\
& $n o$ & $F P$ & $T N$ & $N$ \\
\cline { 2 - 4 } & Total & $P^{\prime}$ & $N^{\prime}$ & $P+N$ \\
\cline { 2 - 4 } & & &
\end{tabular}

Gambar 5 Confusion Matriks
Keterangan:

$\begin{array}{ll}\text { TP } & : \text { True Positives } \\ \text { TN } & : \text { True Neggatives } \\ \text { FN } & : \text { False Negatives } \\ \text { FP } & : \text { False Positives }\end{array}$

\section{Metodologi}

\subsection{Metode Pengumpulan Data}

Metode pengumpulan data yang digunakan dalam penelitian ini adalah pengumpulan data penunjang yang dilakukan dengan pengambilan data-data dari dataset ReDraw ${ }^{1}$. Dataset ReDraw berisi lebih dari 14.382 dasain aplikasi Android yang mencakup 15 komponen GUI. ReDraww: Machine Learning yang berbasis prototyping dari GUI untuk mobile apps. Dataset ini dapat diperoleh melalui website https://www.android-dev-tools.com/redraw. Dari dataset yang digunakan, data citra ini kemudian dibagi menjadi data training, validation dan testing untuk keperluan pembuatan model dan pengecekan model yang terbentuk/ validasi model. Pembagian data menjadi data training, validation dan testing menggunakan scenario $75 \%$ untuk data training, $15 \%$ untuk data validation dan $10 \%$ untuk testing seperti penelitian pada umumnya.

\subsection{Metode Pengolahan Data}

Metode pengolahan data merupakan kerangka penelitian yang telah dikemukakan oleh penulis pada pendahuluan maka penelitian ini menggunakan kerangka sebagai berikut:

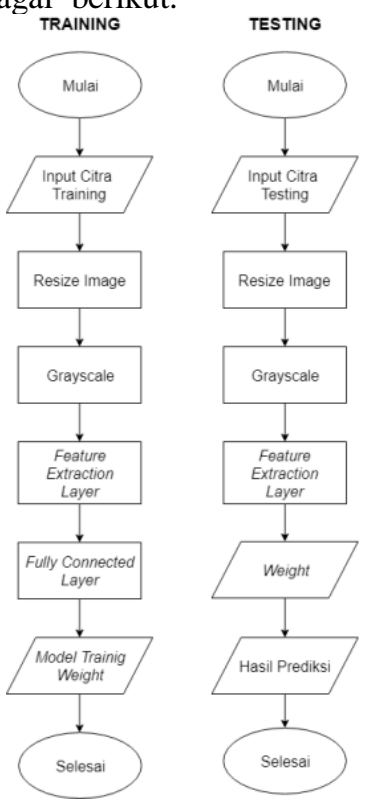

Gambar 6 Rancangan Proses Training dan Testing

Gambar 6 merupakan rancangan proses yang terdapat dalam sistem. Proses training dilakukan untuk mendapatkan nilai bobot unggul yang nantinya akan diuji pada proses testing. Sedangkan 
proses testing dilakukan untuk menguji sistem dengan nilai bobot unggul yang paling unggul dari proses testing. Dimana data siap di cek akurasi ketepatannya setelah dilakukan training.

\subsection{Metode Pengujian}

Dalam metode pengujian terdapat 2 pengujian yang dilakukan yaitu:

- Pengujian Unit

Pengujian unit ditujukan untuk memastikan setiap fungsi berjalan sesuai ketentuam

- Pengujian Akurasi

Pengujian akurasi perhitungan diperlukan untuk menguji tujuan utama dari penelitian ini bahwa dengan menerapkan metode Convolutional Neural Network (CNN) sebagai proses identifikasi komponen GUI.

\section{Perancangan}

\subsection{Deskripsi Sistem}

Aplikasi identifikasi komponen GUI merupakan sebuah peneitian yang akan dikembangkan menggunakan metode Convolutional Neural Network. Terdapat dua proses penting untuk mengidentifikasi komponen GUI yaitu: proses training dan proses testing. Proses training digunakn untuk memperoleh bobot (weight) yang nantinya akan dijadikan model pada proses testing. Sedangkan proses testing digunakan untuk mengindentifikasikan citra berdasarkan model yang telah di training sebelumnya. Pada proses testing user menginputkan citra yang diinginkan untuk di identifikasi.

\subsection{Analisis Sistem}

Dalam algoritma Convolutional Neural Network (CNN) pembentukan arsitektur jaringan dapat mempengaruhi hasil dari akurasi model.
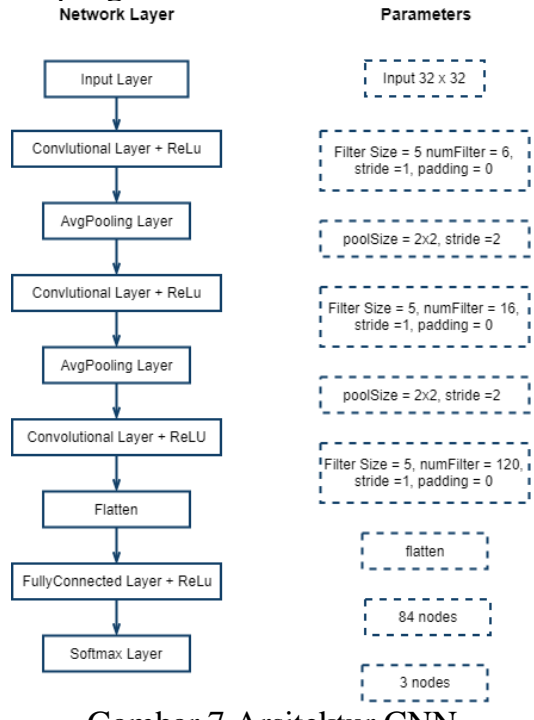

Gambar 7 Arsitektur CNN

Gambar 7 merupakan arsitektur jaringan pada proses training untuk menghasilkan model pada penelitian ini. Penelitian ini menggunakan input gambar dengan ukuran $32 \times 32 \times 1$. Sehingga proses training didapatkan model dari arsitektur tersebut. Gambar 8 Model CNN merupakan model yang terbentuk:

\begin{tabular}{|c|c|c|c|c|c|c|c|}
\hline no & Nama & \multirow{2}{*}{\multicolumn{3}{|c|}{ Size }} & \multicolumn{3}{|c|}{ Parameter } \\
\hline 0 & Input & & & & & & 0 \\
\hline 1 & 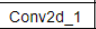 & $\mid\left(\left(32-5+\left(2^{*} 0\right)\right) / 11\right)+1$ & $=$ & $28 * 28 * 6$ & $\left(\left(5^{\star} 5\right)+1\right)^{*} 6$ & $=$ & 156 \\
\hline 2 & MaxPool_1 & & & $14^{*} 14^{*} 6$ & & & 0 \\
\hline 3 & \begin{tabular}{ll|} 
Conv2d_2 \\
\end{tabular} & $\mid\left(\left(14-5+\left(2^{*} 0\right)\right) / 11\right)+1$ & $=$ & $10^{*} 10^{*} 16$ & $\left(\left(5^{*} 5^{*} 6\right)+1\right)^{*} 16$ & $=$ & 2416 \\
\hline 4 & MaxPool_2 & & & $5 * 5 * 16$ & & & 0 \\
\hline 5 & Conv2d_3 & $\mid\left(\left(5-5+\left(2^{*} 0\right)\right) / 11\right)+1$ & $=$ & $1 * 1 * 120$ & $\left(\left(5^{*} 5^{*} 16\right)+1\right)^{*} 120$ & $=$ & 48120 \\
\hline 6 & Flatten & & & 120 & & & 0 \\
\hline 7 & Dense & & & 84 & \begin{tabular}{|l|}
$\left(120^{*} 84\right)+84$ \\
\end{tabular} & $=$ & 10164 \\
\hline 8 & Output & & & 3 & $(84+1) \div 3$ & $=$ & 255 \\
\hline & & & tal & & & & 61111 \\
\hline
\end{tabular}

Gambar 8 Model CNN

\section{Implementasi dan Pengujian}

Melakukan testing pada sistem yang sudah dibuat. Tahap ini dibutuhkan sebagai ukuran bahwa sistem dapat berjalan sesuai tujuan atau bekum. Terdapat beberapa bentuk pengujian dalam penelitian ini, yaitu:

\subsection{Pengujian Sistem}

Pengujian sistem digunakan untuk melihat sistem telah berjalan dengan sesuai atau belum. Pengujian ini dilakukan dengan menguji fitu-fitur dari aplikasi yang dirancang, mulai dari halaman home, pengujian testing input gambar sampai output diperoleh, dan halaman about.

\subsection{Pengujian Akurasi}

Pengujian akurasi dilakukan untuk menguji seberapa besar sistem dapat identifikasi komponen GUI dengan menggunakan metode Convolutional Neural Network. Pada pengujian ini menggunakan sebanyak 136 sampel komponen GUI yang terdiri dari 50 ImageButton, 50 TextView, dan 36 SwitchButton. Hasil confusion matriks adalah sebagai berikut:

Tabel 1. Confusion Matriks

\begin{tabular}{|c|c|c|c|c|}
\hline \multicolumn{2}{|c|}{ Matriks } & \multicolumn{3}{|c|}{ Pred Class } \\
\cline { 3 - 5 } & $\begin{array}{c}\text { Image } \\
\text { Button }\end{array}$ & $\begin{array}{c}\text { Text } \\
\text { View }\end{array}$ & $\begin{array}{c}\text { Switch } \\
\text { Button }\end{array}$ \\
\hline \multirow{3}{*}{$\begin{array}{c}\text { Act } \\
\text { Class }\end{array}$} & $\begin{array}{c}\text { Image } \\
\text { Button }\end{array}$ & 167 & 31 & 2 \\
\cline { 2 - 5 } & $\begin{array}{c}\text { Text } \\
\text { View }\end{array}$ & 17 & 178 & 5 \\
\cline { 2 - 5 } & $\begin{array}{c}\text { Switch } \\
\text { Button }\end{array}$ & 1 & 8 & 27 \\
\hline
\end{tabular}

Berdasarkan Tabel 1. Daiatas merupakan hasil prediksi dari model terhadap data testing menunjukkan hasil yang cukup baik. Perhitungan akurasi dari keseluruhan matriks diatas adalah sebagai berikut:

$$
\begin{gathered}
\text { akurasi }=\frac{\text { prediksi benar }}{\text { jumlah dataset }} \times 100 \% \\
\text { akurasi }=\frac{371}{436} \times 100 \%=85,32 \%
\end{gathered}
$$

Jadi akurasi yang dihasilkan oleh model dengan input citra $32 \times 32$ pixel, learning rate 0,0001 , epoch 1000 didapatkan nilai akurasi sebesar 85,32\% 


\section{Hasil dan Pembahasan}

Pada penelitian ini, peneliti melakukan klasifikasi tiga kelas komponen GUI, yaitu ImageButton, TextView, dan SwitchButton dengan menggunakan algoritma Convolutional Neural Network (CNN) terhadap 3242 dataset dengan perbandingan $75 \%$ training, $15 \%$ validation dan $10 \%$ testing didapatkan hasil akurasi sebesar 85,32\%. Untuk mengetahui faktor-faktor yang mempengaruhi kinerja dari metode CNN, maka dilakukan pengujian dengan menggunakan parameter yang berbeda-beda. Adapun parameter yang di ubah dalam proses pengujian antara lain: Jumlah layer pada proses feature extraction layer, jumlah epoch, pooling layer dan learning rate.

\subsection{Pengujian berdasarkan Jumlah Layer}

Jumlah layer juga dapat mempengaruhi hasil dari akurasi proses training dan testing.

Tabel 2 Hasil Pengujian berdasar Jumlah Layer

\begin{tabular}{|c|c|c|c|}
\hline No & Layer & Accuracy & LossVal \\
\hline 1. & $\begin{array}{c}28 \times 28 \times 6 \text { Konv }+ \\
\text { AvgPool }\end{array}$ & $45.54 \%$ & 8.7782 \\
\hline 2. & $\begin{array}{c}28 \times 28 \times 6 \text { Konv }+ \\
\text { AvgPool }+\end{array}$ & $45.54 \%$ & 8.7551 \\
\hline & $\begin{array}{c}28 \times 28 \times 6 \text { Konv }+ \\
\text { AvgPool }+ \\
10 \times 10 \times 16+\text { A vgPool } \\
+1 \times 1 \times 120 \text { Konv }\end{array}$ & $85,07 \%$ & 0.6906 \\
\hline
\end{tabular}

Berdasarkan Tabel 2 dapat dilihat semakin banyak jumlah layer maka semakin banyak informasi yang didapatkan untuk meningkatkan akurasinya. Namun, semakin banyak layer yang digunakan maka membutuhkan waktu yang lebih lama untuk melakukan proses training maupun testing.

\subsection{Pengujian berdasar Jumlah Epoch}

Epoch adalah ketika seluruh dataset sudah melalui proses training pada Neural Network sampai dikembalikan ke awal dalam satu putaran. Untuk mempermudah dan mempercepat proses training dataset dibagi per batch (batch size). Pada penelitian ini menggunakan batch size sebesar 100, dimana seluruh jumlah dataset akan dibagi dengan ukuran batch size. Tabel 3 berikut adalah hasil perbandingan epoch dari hasil training.

Tabel 3 Akurasi berdasarkan Epoch

\begin{tabular}{|l|l|l|l|l|c|}
\hline Epoch & \multicolumn{1}{|c|}{$\begin{array}{c}\text { Accuracy } \\
\text { Validation }\end{array}$} & $\begin{array}{c}\text { Loss } \\
\text { Validation }\end{array}$ & $\begin{array}{c}\text { Accuracy } \\
\text { Test }\end{array}$ & $\begin{array}{c}\text { Loss } \\
\text { Test }\end{array}$ \\
\hline 100 & $62.31 \%$ & 0.8993 & $57.93 \%$ & 1.0611 \\
\hline 300 & $82.77 \%$ & 0.5327 & $74.71 \%$ & 0.7353 \\
\hline 500 & $84.77 \%$ & 0.4539 & $79.54 \%$ & 0.6242 \\
\hline 700 & $82.92 \%$ & 0.4663 & $80.23 \%$ & 0.5933 \\
\hline 1000 & $85.08 \%$ & 0.6906 & $85.32 \%$ & 0.4603 \\
\hline
\end{tabular}

\subsection{Pengujian Pooling Layer}

Pooling Layer merupakan proses pengurangan ukuran matriks dari hasil proses konvolusi. Proses ini bertujuan untuuk mengurangi nilai parameter sehingga mengendalikan overfitting pada proses training model.

Tabel 4 Akurasi berdasarkan Pooling

\begin{tabular}{|c|c|c|}
\hline Pooling layer & $\begin{array}{c}\text { Accuracy } \\
\text { validation }\end{array}$ & $\begin{array}{c}\text { Loss } \\
\text { validation }\end{array}$ \\
\hline Max Pooling & $46.15 \%$ & 8.6559 \\
\hline Avg Pooling & $85.08 \%$ & 0.4614 \\
\hline
\end{tabular}

Pada Tabel 4 diatas, merupakan percobaan terhadap maxPooling dan averagePooling. Hasil averagePooling dapat dilihat lebih baik daripada maxpooling.

\subsection{Pengujian Nilai Learning Rate}

Penentuan nilai dari learning rate sangat berpengaruh padaa performa hasil. Hasil learning rate adalah sebagai berikut:

Tabel 5 Learning Rate

\begin{tabular}{|c|c|c|}
\hline $\begin{array}{c}\text { Learning } \\
\text { rate }\end{array}$ & $\begin{array}{c}\text { Accuracy } \\
\text { validation }\end{array}$ & $\begin{array}{c}\text { Loss } \\
\text { validation }\end{array}$ \\
\hline 0.01 & $45.69 \%$ & 8.7574 \\
\hline 0.001 & $83.85 \%$ & 0.6124 \\
\hline 0.0001 & $85.23 \%$ & 0.4831 \\
\hline
\end{tabular}

Berdasarkan Tabel 5 dapat dilihat learning rate 0,0001 menunjukkan hasil yang cukup baik dengan accuracy validation sebesar $85.08 \%$ dan accuracy test sebesar $85.32 \%$. Penentuan nilai learning rate yang digunakan pada penelitian ini adalah trial and error, sehingga tidak dapat secara langsung menetukan nilai learning rate yang paling optimum.

\section{Kesimpulan}

Berdasarkan hasil analisis yang telah dilakukam, diperoleh beberapa kesimpulan yaitu:

a. Model CNN yang digunakan pada penelitian ini menggunakan citra berukuran $32 \times 32$, ukuran filter $5 \times 5$, dengan menggunakan hyperparameter learning rate 0.0001 , batch size sebesar 100 dan epoch sebesar 1000. Pembagian data training yang digunakan adalah 3242, validation 650 dan testing 436. Pengujian menghasilkan tingkat akurasi testing dalam melakukan klasifikasi gambar komponen GUI sebesar $85.32 \%$. Tingkat ketepatan untuk mengenali komponen GUI pada prototipe aplikasi mobile ini tergantung dari arsitektur dan hyperparameter yang digunakan untuk mendapatkan hasil yang baik.

\section{Daftar Pustakan}

[1] N. M. Juniver V Mokalu, "Dampak Teknologi Smartphone Terhadap Perilaku Orang Tua di Desa Touure Kecamatan Tompaso," ActaDiurna, vol. 5.1, p. web, 2016.

[2] A'ala, "Deteksi Retak Permukaan Jalan Raya Berbasis Pengolahan Citra Menggunakan Metode 
Ekstaksi Ciri Wavelet," Program Studi Teknik Informatika Fakultas Teknik Universitas Muhammadiyah Yogyakarta, Yogyakarta, 2016.

[3] MockingBot, "What's difference between Wireframe, Prototype \& Mockup?," Medium, 12 September 2016. [Online]. Available: https://medium.com/mockingbot/whats-thedifference-between-wireframe-prototype-mockup17615f77938f. [Accessed 16 May 2019].

[4] S. Sena, "Pengenalan Deep Learning Part7: Convolutional Neural Network (CNN)," Medium, 13 November 2017. [Online]. Available: https://medium.com/@ samuelsena/pengenalandeeplearning-part-7-convolutionalneural-networkcnn-b003b477dc94. [Accessed 28 November 2018].

[5] Prabhu, "Understanding of Convolutional Neural Network (CNN) - Deep Learning," Medium, 4 March 2018. [Online]. Available:

https://medium.com/@RaghavPrabhu/understandingof-convolutional-neural-network-cnn-deep-learning- 99760835f148. [Accessed 20 April 2019].

[6] DanB, "Rectified Linear Units (ReLU) in Deep Learning," Kaggle, 2018. [Online]. Available: https://www.kaggle.com/dansbecker/rectified-linearunits-relu-in-deep-learning. [Accessed 22 Mei 2019].

[7] K. L. Andrea Vedaldi, "MatConvNet: Convolutional Neural Networks for MATLAB.," 2016.

[8] Z. Zhang, "Derivation of Backpropagation in Convolutional Neural Network (CNN)," University of Tennessee, Knoxvill, TN, 2016.

[9] P. E, Data Mining: Konsep dan Aplikasi menggunakan Matlab, 1 ed, Yogyakarta: Andi Offset, 2012. 